\title{
Flipped Classroom for an Active Learning
}

\section{Ana Isabel Santos ${ }^{\circledR}$ Sandro Serpa ${ }^{2}$ (D)}

'University of the Azores, Faculty of Social Sciences and Humanities; Interdisciplinary Centre for Childhood and Adolescence, NICA, Uac, Ponta Delgada, the Azores, Portugal.

Email:ana.is.santos@uac.pt

${ }^{2}$ University of the Azores, Faculty of Social and Human Sciences, Department of Sociology; Interdisciplinary Centre of Social Sciences - CICS.UAc/CICS.NOVA.UAc; Interdisciplinary Centre for Childhood and Adolescence - NICA - UAc, Ponta Delgada, the Azores, Portugal.

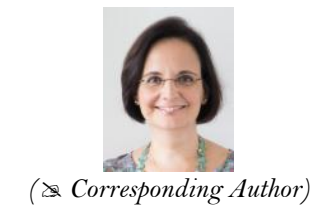

\begin{abstract}
Classes, as a critical teaching-learning process in the school culture, remain, essentially and for the most part, without fundamental changes, following the sequence: presentation of the contents by the teacher, and implementation of these contents in a very theoretical way (highly based on the resolution of exercises, either through worksheets and manuals or through the preparation of written assignments, with or without their oral presentation). This position paper offers another teaching model that reverses this sequence, starting from the student's autonomous work and concluding in the materialisation of the knowledge and skills attained, always with the teacher's support - the flipped teaching method. Through a collection and selection of articles on this topic, concurrently with the authors' experience in training in higher education, and also in the monitoring of students' pedagogical internships, the authors describe and analyse flipped teaching, as well as its limitations and challenges. The results of this analysis suggested that flipped teaching has a high potential in student learning regarding the development and attainment, by them, of specific and transversal competences necessary for the 21 st century, in terms of their employability, entrepreneurship, innovation, literacy and contribution to sustainable development.
\end{abstract}

Keywords: Flipped classroom, Inverted classroom, Reversing teaching, Active learning, Teaching-learning process, Education.

Citation I Ana Isabel Santos; Sandro Serpa (2020). Flipped Classroom for an Active Learning. Journal of Education and eLearning Research, 7(2): 167-173.

History:

Received: 9 April 2020

Revised: 11 May 2020

Accepted: 16 June 2020

Published: 7 July 2020

Licensed: This work is licensed under a Creative Commons Attribution 3.0 License $(\mathrm{cc})$

Publisher: Asian Online Journal Publishing Group
Acknowledgement: Both authors contributed to the conception and design of the study.

Funding: University of the Azores, Interdisciplinary Centre of Social Sciences-CICS.UAc/CICS.NOVA. UAc, UID/SOC/04647/2020, with the financial support of FCT/MEC through national funds and, when applicable, co-financing from FEDER under the PT2020 Partnership Agreement.

Competing Interests: The authors declare that they have no conflict of Competing

Transparency: The authors confirm that the manuscript is an honest, accurate, and transparent account of the study was reported; that no vital features of the study have been omitted; and that any discrepancies from the study as planned have been explained.

Ethical: This study follows all ethical practices during writing.

Contents

1. Introduction

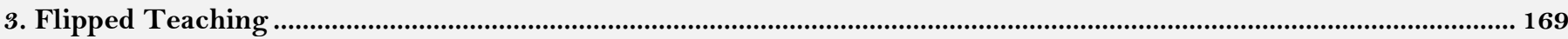

4. Conclusion

References... 


\section{Contribution of this paper to the literature}

This paper discusses the challenges of the inverted or flipped classroom type in education, which is

highly sustained, potentially, and in digital technology.

\section{Introduction}

School culture, whatever the educational level, has traditional components that are very difficult to change. Jacques and Lequeu (2020) sustained that "All teaching/learning activities are focused on the teacher, who must master all the appropriate pedagogical mechanisms, processes and methods. Thus, everything is designed in such a way as to remove the possibility of error completely". Classes, as a central teaching-learning process in this school culture, are characterized, in their great generality, as having been maintained, essentially, without fundamental changes. Classes, as a critical teaching-learning process in this school culture, remain, essentially and for the most part, without fundamental changes (Jacques \& Lequeu, 2020; Seedoyal-Seereekissoon, 2019) following the sequence: presentation of the contents by the teacher, and implementation of these contents in a very theoretical way (highly based on the resolution of exercises, either through worksheets and manuals or through the preparation of written assignments, with or without their oral presentation).

However, this type of traditional class, which is generally very much centred on lectures by the teacher (Arends, 1999) has limitations. Among these, to be highlighted that, in a traditional class centred on the transmission of knowledge by the teacher, the student's ability to concentrate and apprehend information decreases after about an hour. Likewise, interaction with the student is very low, which hinders, for example, the questioning of the student, while the expected passivity of the student reduces his/her interest and ability to apprehend knowledge (Joksimović et al., 2019). In a systematic way, Joksimović et al. (2019) explained the reasons that prompted a shift in the form of teaching in a specific situation, which can be transposed, with due care, to other contexts as shown in Table 1.

Table-1. Difficulties with the old teaching methodology.

Students were attending classes without any prior knowledge. A lot of time was spent for explaining the basics.

During the lectures students were passive and bored. It was a big hindrance to a learning process.

The lectures lacked teacher- student interaction, necessary for successful learning process.

Very often a lot of tasks shown during lectures had to be repeated afterwards, during exercise period.

Because of the slow progress, students were losing interest for the subject very fast.

Source: Joksimović et al. (2019).

This takes place in a context in which the majority of students are immersed in digital culture (Jacques \& Lequeu, 2020; Santos \& Serpa, 2020; Santos. \& Serpa, 2017). Thus, the teacher must also start from his/her traits (Arends, 1999) mobilise his/her students' traits (Joksimović et al., 2019) and also have in mind the technological resources available as strategies that better allow knowledge construction (Arends, 1999; Junio \& Bandala, 2019).

Escudero Fernández (2020) offered the already classic proposal and with high heuristic potential by Chickering and Gamson (1989) on seven principles of good practice in university education and which, with the necessary adaptations, should be considered in all teaching-learning situations as shown in Table 2.

Table-2. Seven principles of good practice in undergraduate university education

\begin{tabular}{l|l}
\hline 1. Contact between students and teachers. & $\begin{array}{l}\text { The contact inside and outside the classroom between both actors favours } \\
\text { the participation and motivation of the student regarding his/her learning. } \\
\text { Teachers are also role and values models. }\end{array}$ \\
\hline $\begin{array}{l}\text { 2. Reciprocity and cooperation between } \\
\text { students. }\end{array}$ & $\begin{array}{l}\text { Learning improves when it is a team, collaborative and social work. The } \\
\text { process of sharing ideas fosters the critical spirit. }\end{array}$ \\
\hline 3. Active learning. & $\begin{array}{l}\text { Students must be active actors in the process and be involved in their } \\
\text { learning. }\end{array}$ \\
\hline 4. Quick feedback. & $\begin{array}{l}\text { Quality learning is based on the information students need to be aware of } \\
\text { the knowledge and competences that have been attained and those that } \\
\text { have not. Students require opportunities during the programme to analyse } \\
\text { and reflect on what they have learned and what they still have to learn. }\end{array}$ \\
\hline 5. Dedicated time. & $\begin{array}{l}\text { Allocating adequate and realistic time to each task favours effective student } \\
\text { learning and lays the foundation for high performance. }\end{array}$ \\
\hline 6. High expectations & $\begin{array}{l}\text { Focusing on high expectations for all students to improve regardless of } \\
\text { each student's level of preparation. }\end{array}$ \\
\hline 7. Diversity in learning mechanisms. & $\begin{array}{l}\text { Learning is not a one-way process, each student can respond better to some } \\
\text { learning strategies than to others, so they must have the opportunity to } \\
\text { show their potential, which will enable them to respond positively to the } \\
\text { effort involved in learning the strategies or contents that are not easy for } \\
\text { them. }\end{array}$ \\
\hline Source: Translated from Chickering and Gamson (1989) cited in Escudero Fernández (2020).
\end{tabular}

The need to motivate students, without reducing the level of demand of the learning objectives, is vital today (Jacques \& Lequeu, 2020) and this is one of the reasons for the growing interest in the flipped classroom model (Stöhr \& Adawi, 2018).

However, when approaching the concept of flipped classroom, it is necessary to acknowledge that it is not univocal (Ahmed \& Asiksoy, 2018; Deng, 2020; Escudero Fernández, 2020; Jacques \& Lequeu, 2020; Jang \& Kim, 2020; López Collazo, Rodríguez Jiménez, \& Dávila Valdés, 2019; Schmeisser Arriaga \& Medina-Talavera, 2018). This work regards the flipped classroom as a type of pedagogical form or teaching strategy that begins with a more autonomous work by students, through the mobilisation of technology for the study of content outside the classroom, and only then will there be classroom activities, preferably of a more practical nature, to build and 
strengthen each student's knowledge. Jacques and Lequeu (2020) characterise this type of classes "as those in the inverted/flipped classroom model, which consists of reversing the nature of in-class and out-of-class activities.

This position paper offers this teaching model that reverses the sequence, starting from the student's autonomous work and concluding in the materialisation of the knowledge and competences attained, always with the teacher's support - the inverted classroom, and also discusses the challenges that this different type of educational process poses.

The paper will focus particularly on the type of inverted or reversed classroom called flipped teaching, which is highly sustained, potentially, in digital technology. Through a collection and selection of articles on this topic, concurrently with the authors' experience in training in higher education but also in the monitoring of the pedagogical internships of students in other educational levels, the authors describe and analyse flipped teaching, as well as its limitations and challenges.

\section{Methods}

The authors carried out the bibliographic search through the B-ON and SCILIT databases, through the search for articles that had in the title and/or the Abstract the following terms: "flipped teaching", "inverted classroom" or "reversed teaching". B-ON (Biblioteca do Conhecimento Online) "provides unlimited and permanent access to research and higher education institutions to the full texts of thousands of scientific journals and online e-books from some of the most important content providers" (Biblioteca do Conhecimento Online, online).

From the articles obtained and shown (the most recent is dated 21-5-2020), the authors selected the relevant ones through several cumulative stages: (2) reading of the title; (2) reading of the abstract; and (3) reading of the full article, to fulfil the goal of putting forth another teaching model that inverts this sequence, starting from the student's autonomous work and concluding in the materialisation of the knowledge and competences attained in the process, always with the teacher's support - a flipped teaching -, also discussing the challenges that this different type of teaching poses.

\section{Flipped Teaching}

\subsection{Presentation}

The concept of flipped classroom sometimes emerges in a not entirely univocal way, either internally or in its relationship with the inverted classroom. However, the key element is that the traditional way of teaching and learning is inverted (Burnham \& Mascenik, 2018; Deng, 2020; Junio \& Bandala, 2019; Peñaranda, Alfonso, Jiménez, \& Antón, 2018) and the "classroom [is a] time for learner-centred activities, such as active and problem-based learning” (Joksimović et al., 2019) as can be seen in Table 3.

Table-3. The 5 main components of an inverted classroom according to Bergmann and Sams (2012).

\begin{tabular}{l|l}
\hline 1 & Set clear learning goals. \\
\hline 2 & $\begin{array}{l}\text { Determine which of these objectives best meet the goals and how to apply direct and clear instructions to } \\
\text { better capture them. }\end{array}$ \\
\hline 3 & Ensure that the students have access to videos. \\
\hline 4 & Incorporate learning activities that will be carried out in class. \\
\hline 5 & $\begin{array}{l}\text { Create several types of assessment for the student to demonstrate his/her mastery of each learning } \\
\text { objective in each particular unit of study. }\end{array}$ \\
\hline Source: Translated from Schmeisser Arriaga and Medina-Talavera (2018).
\end{tabular}

The inverted classroom then implies, in a way, to invert the logic of the classes (Schmeisser Arriaga \& MedinaTalavera, 2018; Vieira \& Ribeiro, 2018): "to carry out at home what is normally done in class, and in class what is traditionally done at home as homework" (López Collazo et al., 2019). Regarding the technology associated with this form of teaching and learning, Valerjevna et al. (2020) maintained that:

The Inverted Classroom technology allows organizing preconditions for the self-directed learning within the formal education framework. The acquisition of syllabus and competencies is organized the way that each student works under his/her own tempo, using the methods and tools that are common to modern student.

The method underlying this teaching-learning process is depicted graphically in Figure 1, as an example.

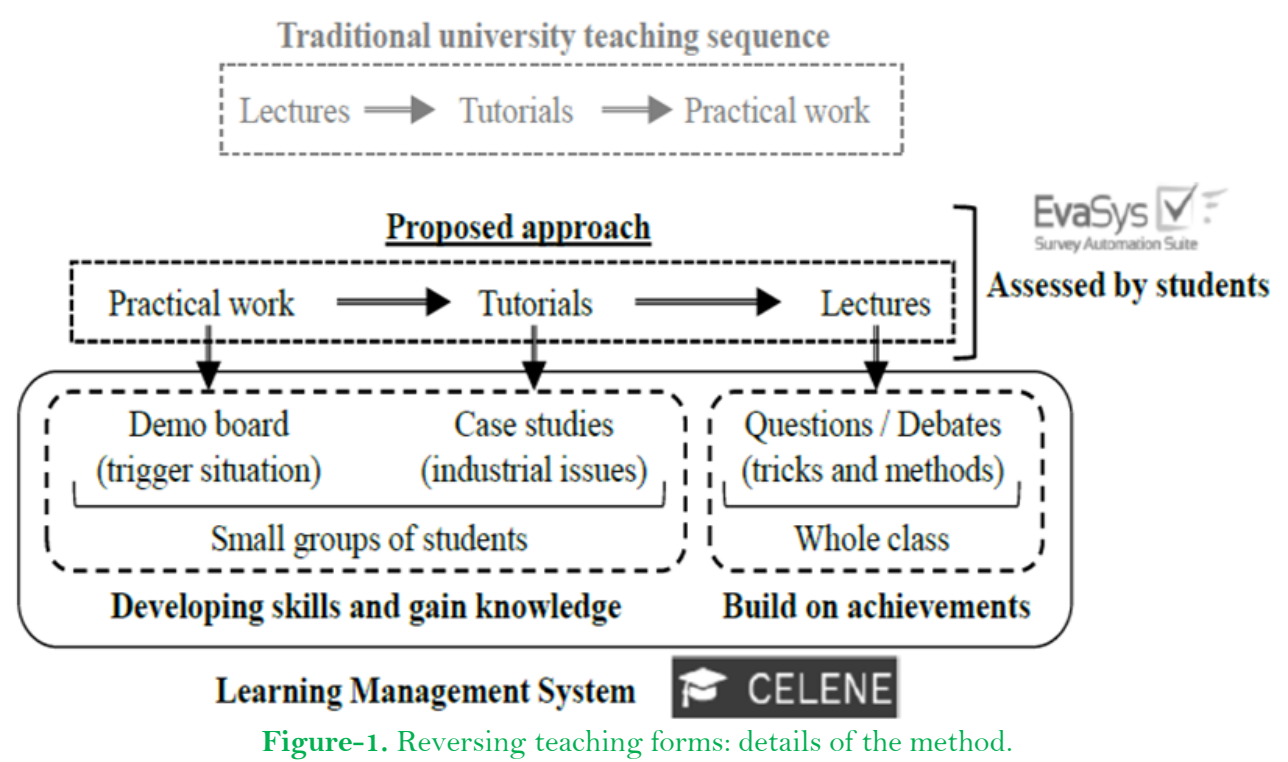


In this work, the authors will consider the Flipped Classroom as a way of implementing the Inverted Classroom. According to Junio and Bandala (2019) an increasing number of teaching institutions and teachers have adopted the teaching-learning process based on the Flipped Classroom model, especially in situations and contexts in which typical and traditional resources used in classes and homework for a given course are reversed. According to this method, the teaching-learning process is a dynamic and interactive process, in which the student takes on the central role in his/her learning, and the teacher has the role of advisor and enabler of this process of knowledge attainment by the student.

The Flipped Classroom teaching methodology tends to take some teaching-learning processes outside the classroom, that is:

[...] the students prepare the subjects outside the alma mater, through the use of information and communication technologies (TIC) and uses time in the classroom to carry out activities that require greater participation and student - teacher interaction, to debate ideas and development of constructs and mindfacts appropriate to generational change, management that is sustained with the support of new technologies" (Aznar, Prada, Acevedo, Durán-Flórez, \& Gómez, 2019).

Flipped Classroom itself may have variants (Stöhr \& Adawi, 2018). For example, the Flipped Learning Network (FLN) (2014) distinguishes Flipped Classroom from Flipped Learning as shown in Table 4. According to this Network:

Flipped Learning is a pedagogical approach in which direct instruction moves from the group learning space to the individual learning space, and the resulting group space is transformed into a dynamic, interactive learning environment where the educator guides students as they apply concepts and engage creatively in the subject matter (Flipped Learning Network (FLN), 2014).

Table-4. Flipped learning, the four pillars of F-L-I-PTM

\begin{tabular}{|c|c|}
\hline $\begin{array}{l}\text { Flexible } \\
\text { Environment }\end{array}$ & $\begin{array}{l}\text { Flipped Learning allows for a variety of learning modes; educators often physically rearrange their } \\
\text { learning spaces to accommodate a lesson or unit, to support either group work or independent study. } \\
\text { They create flexible spaces in which students choose when and where they learn. Furthermore, } \\
\text { educators who flip their classes are flexible in their expectations of student timelines for learning and } \\
\text { in their assessments of student learning. }\end{array}$ \\
\hline $\begin{array}{l}\text { Learning } \\
\text { Culture }\end{array}$ & $\begin{array}{l}\text { In the traditional teacher-centered model, the teacher is the primary source of information. By } \\
\text { contrast, the Flipped Learning model deliberately shifts instruction to a learner-centered approach, } \\
\text { where in-class time is dedicated to exploring topics in greater depth and creating rich learning } \\
\text { opportunities. As a result, students are actively involved in knowledge construction as they participate } \\
\text { in and evaluate their learning in a manner that is personally meaningful. }\end{array}$ \\
\hline $\begin{array}{l}\text { Intentional } \\
\text { Content }\end{array}$ & $\begin{array}{l}\text { Flipped Learning Educators continually think about how they can use the Flipped Learning model to } \\
\text { help students develop conceptual understanding, as well as procedural fluency. They determine what } \\
\text { they need to teach and what materials students should explore on their own. Educators use Intentional } \\
\text { Content to maximize classroom time in order to adopt methods of student-centered, active learning } \\
\text { strategies, depending on grade level and subject matter. }\end{array}$ \\
\hline $\begin{array}{l}\text { Professional } \\
\text { Educator }\end{array}$ & $\begin{array}{l}\text { The role of a Professional Educator is even more important, and often more demanding, in a Flipped } \\
\text { Classroom than in a traditional one. During class time, they continually observe their students, } \\
\text { providing them with feedback relevant in the moment, and assessing their work. Professional } \\
\text { Educators are reflective in their practice, connect with each other to improve their instruction, accept } \\
\text { constructive criticism, and tolerate controlled chaos in their classrooms. While Professional Educators } \\
\text { take on less visibly prominent roles in a flipped classroom, they remain the essential ingredient that } \\
\text { enables Flipped Learning to occur. }\end{array}$ \\
\hline
\end{tabular}

If well implemented, the Flipped Classroom fosters active learning (Vieira \& Ribeiro, 2018) as addressed in the next section.

\subsection{Active Learning}

The Flipped Classroom, based on constructivism, fosters active learning (Deng, 2020; Escudero Fernández, 2020; Junio \& Bandala, 2019; Kühl et al., 2019; Shapran, 2019; Stöhr \& Adawi, 2018) and is an important methodology to leverage the active construction of knowledge. Students learn in a more consolidated way the contents of the courses and there is a better and more fruitful interaction between the students, and between them and the teachers.

Flipped classroom fosters students' sense of belonging to the community - which stems from their sharing of knowledge and experiences with others - and allows them to work and develop their communication competences and take on their points of view, as a result of the appropriation of content and knowledge. Table 5 depicts the motivations for adopting the inverted classroom method.

Table-5. Motivations for introducing an inverted classroom

\begin{tabular}{l} 
- Enable active learning and a learner centered education \\
- Teach students to become effective self-learners \\
- Enable students to learn at their own pace, especially in heterogeneous groups of \\
students \\
- Use more practice and problem solving activities in lecture \\
- Repeat the content in different forms \\
- Enable students to repeat the course lecture content \\
- Have the possibility to cover more content \\
\hline Source: Ulrich (2019).
\end{tabular}

According to Schmeisser Arriaga and Medina-Talavera (2018) With the inverted classroom, the role of the student and the teacher changes. The attainment of the training is now carried out by the student autonomously 
and at his/her own pace, based on the proposed teaching materials. The teachers' work consists, on the one hand, of designing activities, both for prior study and to be carried out in class using different techniques that foster students' active and cooperative learning and, on the other hand, of becoming an enabler and a leader of the teaching-learning process.

\subsection{Challenges}

Inverted classroom teaching generally entails several challenges (Jang \& Kim, 2020) and some of them are listed in Table 6.

Table-6. Challenges of the inverted classroom method.

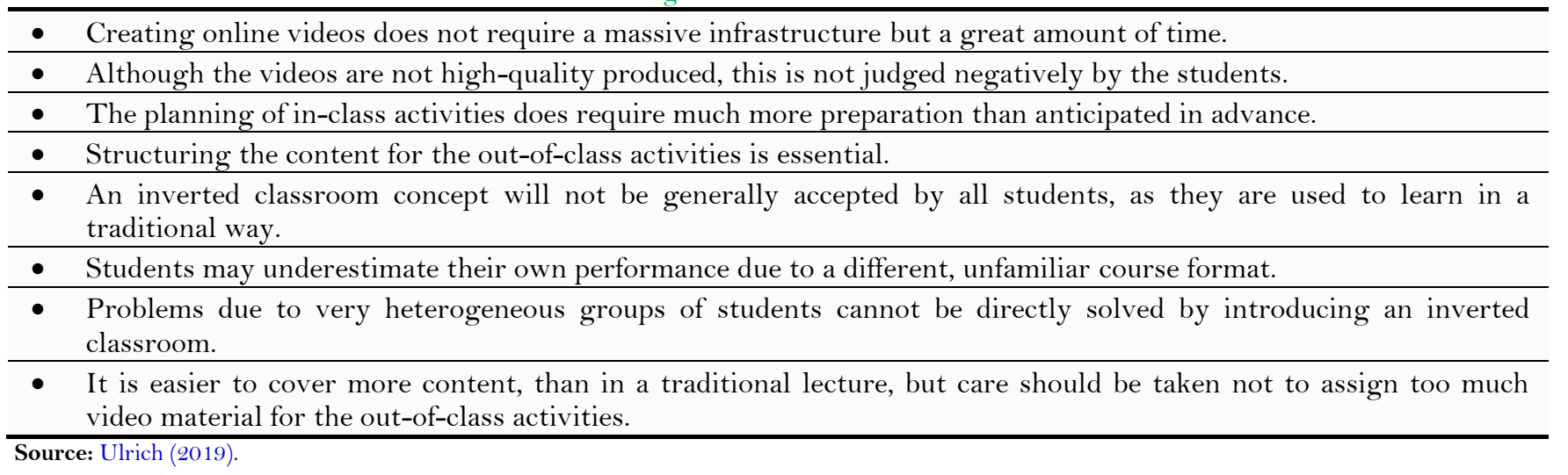

In the specific case of the Flipped Classroom, students learn given content at home. After this stage of the process, the classroom becomes an active learning environment, in which students implement the concepts they have learnt independently. In this new way of conducting the teaching-learning process, the teacher moves from conveyer of content and knowledge to enabler of its attainment and appropriation by students. In an inverted class, students desirably come for the class prepared, as they will have already interacted and learnt the content of the course downstream from the face-to-face class, which reduces the cognitive burden associated with lectures (Petillion \& McNeil, 2020) Table 7.

Table-7. Design principles required for the flipped classroom.

\begin{tabular}{l}
\hline Introducing students to the primary knowledge ahead of class activities \\
\hline Motivates students in preparation for the class activities by watching online lectures \\
\hline Structuring the evaluation methods \\
\hline Bringing a connection between activities performed within the classroom and those performed outside the classroom \\
\hline Provision of appropriate guidance to the students \\
\hline Helps students to form a community of learners \\
\hline Provides quick reaction or feedback about practice work
\end{tabular}

To attain the flipped classroom objectives, it is, naturally, necessary to introduce changes in the traditional teaching-learning process, notably through its reformulation as shown in Table 8.

Table-8. (Re)formulation of the teaching-learning process.

\begin{tabular}{l|l}
\hline 1 & Workshops aimed at instructing the new approach and how to use the new approach designing tasks \\
\hline 2 & $\begin{array}{l}\text { Online sessions aimed at reviewing the knowledge learned in the workshop and applying the new } \\
\text { approach to make a lesson design }\end{array}$ \\
\hline 3 & Comments from peers and the instructor \\
\hline 4 & Revision based on the comments \\
\hline
\end{tabular}

\subsubsection{Teachers}

The teacher's role undergoes profound changes, and he/she no longer controls so intensely the work carried out by the students. This innovation entails, for the teacher, higher anxiety in class preparation (Deng, 2020; Vieira \& Ribeiro, 2018) and in addressing the questions raised and found by his/her students, which will tend to be more complex, demanding and unforeseen (Escudero Fernández, 2020; Junio \& Bandala, 2019; López Collazo et al., 2019; Shapran, 2019). According to the flipped classroom premises:

The teacher cooperates with students in the process of their learning, there appears a joint contribution to the learning process. The inverted model places great responsibility for learning on the students, giving them an incentive for genuine professional development. Educational activities can be led and controlled by students, and communication between students can become a propelling power of the process (Valerjevna et al., 2020).

Deng (2020) advocates the centrality of mutual assessment between teachers and students in this teachinglearning system. It is vital that teachers fully and unequivocally understand the students' knowledge structure when planning their course so that this process is effective and students attain, in fact, the learning objectives autonomously and prior to the face-to-face class. The author adds that, in the flipped classroom, the teacher and student roles are reversed, as students prepare their class, think and analyse their knowledge as if they were teachers (Deng, 2020).

In this process, there is the need to assess the impact of the process during and at the end, which should flexible in case of need for reformulation (Ulrich, 2019). 


\subsubsection{Students}

In this learning process, the student is ascribed greater responsibility and even more work and motivation (López Collazo et al., 2019) making it impossible for him/her to take a passive role in his/her learning. This may generate satisfaction (Aznar et al., 2019; Escudero Fernández, 2020; Musdi, Dewi, \& Tasman, 2019) but also displeasure, as well as lower grades (Junio \& Bandala, 2019; Ulrich, 2019). It is even possible to find variations by gender, for example, or in the stress levels experienced (Kaur \& Kauts, 2020).

In the Flipped Classroom process, the student starts to play a critical and active role (Vieira \& Ribeiro, 2018). Unlike traditional theoretical classes, in which the teacher's role is basically to convey content and that of the students is to passively receive it, in this new system, students have access to the content before the class, which allows them to much greater autonomy in terms of time management and the different formats of the materials they research for the preparation of the class (printed information, videos,...).

After this preparation, the students go to class with knowledge that they mobilise in problem-solving, discussion of pertinent issues and group work. In the third stage of this process of knowledge appropriation by students, they, once again outside the classroom, may develop projects that allow them to consolidate the knowledge learnt and allow their assessment by the teacher (Vieira \& Ribeiro, 2018). In the same vein, Ulrich (2019) argued that "This concept shifts the educational perspective from a teacher centered learning environment to a learner centered environment".

This learning process may foster interdisciplinarity (Junio \& Bandala, 2019; Valerjevna et al., 2020) as well as the attainment of both specific and transversal competences (Kühl et al., 2019; Peñaranda et al., 2018; Sá \& Serpa, 2018) but it also entails profound challenges (Vieira \& Ribeiro, 2018).

\section{Conclusion}

As a basic idea, we corroborated the position that critical thinking and the attainment of other transversal competences is favoured in flipped instruction (Junio \& Bandala, 2019; López Collazo et al., 2019) involving a profound shift in the way of teaching (Wulansari and Kusumaningrum (2020).

The flipped classroom pedagogical strategy entails a profound innovation and transformation of a secular teaching model, which is perpetuated with slight changes and implies a profound shift in school culture (times, ways of teaching and learning, ways of assessing, teacher-student relationship,...). This change materialises in the practices and expectations of stakeholders, such as teachers, students and other individual and collective actors (parents, directors, politicians,...) (Deng, 2020; Valerjevna et al., 2020; Wulansari \& Kusumaningrum, 2020).

However, for the flipped classroom to be successful, in addition to adaptation and preparation by the teachers, it is also critical that the student takes on a responsible autonomy stance (Valerjevna et al., 2020) in a context in which instruction takes place in a more flexible learning environment, very different from the traditional lecturestyle (Junio \& Bandala, 2019). If this teaching-learning system is not very carefully planned and explained to all stakeholders, it will generate anxiety and learning difficulties, which result in profound resistance (Junio \& Bandala, 2019; Seedoyal-Seereekissoon, 2019).

It was concluded that flipped teaching, if well implemented, has a high potential for student learning (Jacques \& Lequeu, 2020; Joksimović et al., 2019; Petillion \& McNeil, 2020) in their preparation for the competences needed for the $21^{\text {st }}$ century, in terms of their employability, entrepreneurship, innovation, literacy and contribution to sustainable development, which does not invalidate the need for further studies (Jang \& Kim, 2020).

A class does not necessarily have to take place in a predefined physical space, and the COVID-19 pandemic that the world is going through has demonstrated it and may have triggered the increase in this other type of education. Today's world witnesses distance learning, favouring contact through the digital world, with a higher degree of responsibility of the student for his/her learning process, less dependent, in many cases, on the presence of the teacher, who, more and more, seems to take on the role of enabler and advisor of processes that are often discussed, analysed and looked into up in synchronous work sessions, in search of a higher understanding and apprehension of the contents and processes attached to them.

\section{References}

Ahmed, H. D., \& Asiksoy, G. (2018). Flipped classroom in language studies: A content analysis of recent articles. Near East University Online Journal of Education, 1(1), 11-19.Available at: https://doi.org/10.32955/neuje.v1i1.52.

Arends, R. I. (1999). Learning to teach. Lisbon: McGraw-Hill.

Aznar, I., Prada, D. A., Acevedo, A., Durán-Flórez, F., \& Gómez, J. (2019). Measurement of the performance of the inverted classroom methodology in the finance learning environment: A comparison with the traditional class. Paper presented at the In Journal of Physics: Conference Series. IOP Publishing.

Burnham, K. D., \& Mascenik, J. (2018). Comparison of student performance and perceptions of a traditional lecture course versus an inverted classroom format for clinical microbiology. Journal of Chiropractic Education, 32(2), 90-97.Available at: https://doi.org/10.7899/jce$17-21$.

Chen, H. C., \& Tian, J. X. (2020). Developing and evaluating a flipped corpus-aided English pronunciation teaching approach for pre-service teachers in Hong Kong. Interactive Learning Environments, 1-14.Available at: https://doi.org/10.1080/10494820.2020.1753217.

Chickering, A. W., \& Gamson, Z. F. (1989). Seven principles for good practice in undergraduate education. Biochemical Education, 17(3), 140141.Available at: 10.1016/0307-4412(89)90094-0.

Deng, F. (2020). Research on the flipped college English cass based on "Knowledge Internalization". Journal of Language Teaching and Research, 11(3), 467-472.Available at: https://doi.org/10.17507/jltr.1103.15.

Escudero Fernández, S. (2020). Flipped classroom: Practical application using lessons in lab practice for an engineering subject. ArDIn. Art, Design and Engineering, 9, 27-48.Available at: https://doi.org/10.20868/ardin.2020.9.4120.

Flipped Learning Network (FLN). (2014). The four pillars of F-L-I-PTM. Retrieved from: https://flippedlearning.org/definition-of-flippedlearning/.

Jacques, S., \& Lequeu, T. (2020). The attractiveness of reversing teaching forms - feedback on an electrical engineering course. International Journal of Engineering Pedagogy (iJEP), $10(3), 21-34$.Available at: https://doi.org/10.3991/ijep.v10i3.12361.

Jang, H. Y., \& Kim, H. J. (2020). A meta-analysis of the cognitive, affective, aand interpersonal outcomes of flipped classrooms in higher education. Education Sciences, 10(4), 115.Available at: https://doi.org/10.3390/educsci10040115.

Joksimović, A. D., Veg, E. A., Simonović, V. D., Regodić, M. M., Šiniković, G. B., \& Gubeljak, N. (2019). Implementation of inverted classroom methodology in 3D modeling course. FME Transactions, 47(2), 310-315.Available at: https://doi.org/10.5937/fmet 1902310j. 
Junio, D. A., \& Bandala, A. A. (2019). Innovating academic writing through flipped classroom instruction. Paper presented at the 2019 IEEE 11 th International Conference on Humanoid, Nanotechnology, Information Technology, Communication and Control, Environment, and Management (HNICEM). Laoag, Philippines, 29 Nov.-1 Dec.

Kaur, A., \& Kauts, A. (2020). Effect of flipped classroom instructional strategy on academic stress. Journal of Xidian University, 14(5), 23992411.

Kühl, S. J., Schneider, A., Kestler, H. A., Toberer, M., Kühl, M., \& Fischer, M. R. (2019). Investigating the self-study phase of an inverted biochemistry classroom-collaborative dyadic learning makes the difference. BMC Medical Education, 19(1), 64.Available at: https://doi.org/10.1186/s12909-019-1497-y.

López Collazo, Z. S., Rodríguez Jiménez, A., \& Dávila Valdés, Y. (2019). Pedagogical experience in the implementation of the inverted class in the academic training process. ECIPeru Magazine, 59-65.

Musdi, E., Dewi, A. A. R., \& Tasman, F. (2019). Students' perception toward flipped classroom learning. Journal of Physics: Conference Series, 1317(1), 012132.Available at: 10.1088/1742-6596/1317/1/012132.

Peñaranda, D. S., Alfonso, C. N., Jiménez, F. M., \& Antón, J. S. V. (2018). Flipped classroom and ICTs as the tools to reach key competences. Paper presented at the Proceedings of the 4th International Conference on Higher Education Advances (HEAd'18). València, Universitat Politècnica de València, June 20-22.

Petillion, R. J., \& McNeil, W. S. (2020). Johnstone's triangle as a pedagogical framework for flipped-class instructional videos in introductory chemistry. Journal of Chemical Education, 97(6), 1536-1542.Available at: 10.1021/acs.jchemed.9b01105.

Sá, M. J., \& Serpa, S. (2018). Transversal competences: Their importance and learning processes by higher education students. Education Sciences, 8(3), 126.Available at: https://doi.org/10.3390/educsci8030126.

Santos, A., \& Serpa, S. (2020). Literacy: Promoting sustainability in a digital society. Journal of Education, Teaching and Social Studies, 2(1), 19.Available at: https://doi.org/10.22158/jetss.v2n1p1.

Santos., A., \& Serpa, S. (2017). The importance of promoting digital literacy in higher education. International Journal of Social Science Studies, 5(6), 90-93.Available at: https://doi.org/10.11114/ijsss.v5i6.2330.

Schmeisser Arriaga, C. M., \& Medina-Talavera, J. A. (2018). Comparative study between the flipped classroom methodology and the traditional methodology in Spanish, English and mathematics classes. MLS Educational Research, 2(2), 159-176.

Seedoyal-Seereekissoon, D. (2019). Flipped classroom versus traditional teaching and learning from students' perspective at interdisciplinary level. Case: Middlesex University Mauritius

Shapran, O. (2019). Features of using «Flipped Learning» technology in higher education institutions. Professional Education: Methodology, Theory and Technologies, 9, 226-243.

Stöhr, C., \& Adawi, T. (2018). Flipped classroom research: From "Black Box" to "White Box" evaluation. Education Sciences, 8(1), 22.Available at: https://doi.org/10.3390/educsci8010022.

Ulrich, B. (2019). Introducing an inverted classroom concept for an undergraduate course in Power Electronics - Implementation, evaluation and experiences. Paper presented at the Proceedings of the 20th International Conference on Research and Education in Mechatronics (REM). Wels: IEEE.

Valerjevna, K. N., Paul, V., Pavlovna, V. N., Anatoljevich, B. A., Aleksandrovna, V. E., \& Aleksandrovna, B. A. (2020). Inverted classroom as innovative international educational technology in teaching doctors in global challenges era, in: J.Veber, L.Guzikova (Eds.) Proceedings of the "New Silk Road: Business Cooperation and Prospective of Economic Development" (NSRBCPED 2019) (pp. 755-760). Paris: Atlantis Press.

Vieira, H., \& Ribeiro, C. P. (2018). Implementing flipped classroom in history: The reactions of eighth grade students in a Portuguese school. Yesterday and Today, 19, 35-49.Available at: https://doi.org/10.17159/2223-0386/2018/n18a3.

Wulansari, A., \& Kusumaningrum, W. R. (2020). The digital native voices in a flipped classroom. Journal Sosioteknologi, 19(1), 176-187. 